\title{
XCVII. The motion of electrons in gases
}

\author{
J.S. Townsend M.A. F.R.S. \& V.A. Bailey M.A.
}

To cite this article: J.S. Townsend M.A. F.R.S. \& V.A. Bailey M.A. (1921) XCVII. The motion of electrons in gases, Philosophical Magazine Series 6, 42:252, 873-891, DOI: 10.1080/14786442108633831

To link to this article: http://dx.doi.org/10.1080/14786442108633831

$$
\text { 曲 Published online: } 08 \text { Apr } 2009 .
$$

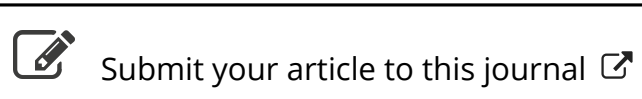

\section{Џll Article views: 31}

Q View related articles $\square$

7 Citing articles: 78 View citing articles $\square$ 
T H E

\title{
LONDON, KDINBURGH, AND DUBLIN
}

\section{PHILOSOPHICAL MAGAZINE}

\author{
AND \\ JOURNAL OF SCIENCE.
}

[SIXTH SERIES.]

DECEMBER 1921.

XCVII. The Motion of Electrons in Gases. By J. S. Townsend, M.A., F.R.S., Wykeham Professor of Physics, Oxford, and V. A. BAILEY, M.A., Queen's College, Oxford ${ }^{*}$.

1. $N$ some previous researches published in the Proceedings of the Royal Society, a full account has been given of the determination of the motion of electrons in air from measurements of the divergence of a stream moving in a uniform electric field, and the deflexion of the stream by a transverse magnelic force.

The pressure of the air was varied from about a quarter of a millimetre of mercury to 20 millimetres, and the electric force from about 4 volts to 40 volts per centimetre, which were found to be the most suitable ranges of the pressure and electric force for observing the motion of free electrons, when the velocity of agitation exceeds the velocity in the direction of the electric force.

We give in this paper a brirf account of the method of finding the velocities of the electrons and the application of the results to determine some properties of the molecules of gases. The paper also contains results of a large number of experiments which have recently been made on the motion of electrons in hydrogen, nitrogen, and oxygen, with ranges of forces and pressures similar to those used in the experiments with air.

* Communicated by the Authors.

Plil. Mag. S. 6. Vol, 42. No. 252. Dec. 1921. 
In the earlier investigations it was found that the motion of electrons in hydrogen and other gases was similar to that obtained in air, but only a few experiments were made with these gases.

2. One of the principal differences which was observed between the motion of ions and the motion of free electrons* in gases, is that the mean kinetic energy of the motion of agitation of an ion is the same as that of a molecule of the gas, whereas with electrons the energy of agitation increases with the force, and with the smaller pressures and larger forces used in these experiments the mean kinetic energy of agitation of an electron is as great as a hundred times that of a molecule of the gas. The reason for this is that the electron loses only a small part of the energy which it acquires in moving under the electric force when it collides with a molecule, since the mass of a molecule is so large compared with that of an electron. Thus the effect of a collision with a molecule is to alter the direction of motion of the electron without making much reduction in the velocity. The average loss of energy in a collision with a molecule is somewhat greater than the loss which would take place if the electron and the molecule were perfectly elastic spheres, but this loss is so small that the velocity of agitation becomes very large.

In order to obtain definite information as to the nature of the collisions of electrons with molecules of a gas, it is necessary to determine experimentally both the mean velocity of agitation $u$ and the mean velocity $W$ in the direction of the electric force. Tiıe factor $k$ by which the mean energy of agitation $m u^{2} / 2$ of an electron exceeds that of a molecule of the gas, and the velocity $\mathrm{W}$ in the direction of the electric force $Z$, were determined by means of the apparatus which was found to be most suitable for determining these quantities for electrons moving in air $\dagger$.

3. The principle of the method is shown by the diagram fig. 1.

Electrons are set free from a metal plate $\mathrm{A}$ by the action of ultra-violet light and travel through the gas to a parallel plate $B$ which is at a distance of 4 centimetres from A. The middle part of the plate $B$ is of thin brass foil with a slit 2 millimetres wide and $1 \frac{1}{2}$ centimetres long in the centre, through which some of the electrons pass in a narrow stream into the lower part of the apparatus and are received on the

* Proc. Roy. Soc. A, lxxxi. p. 464 (1908).

+ J. S. Townsend and H. T. Tizard, Proc. Roy. Soc. A, Ixxxviii. p. 336 (1913). 
three electrodes $\mathrm{E}_{1}, \mathrm{E}_{2}, \mathrm{E}_{3}$ at a distance of 4 centimetres from the plate $B$.

Fig. 1.
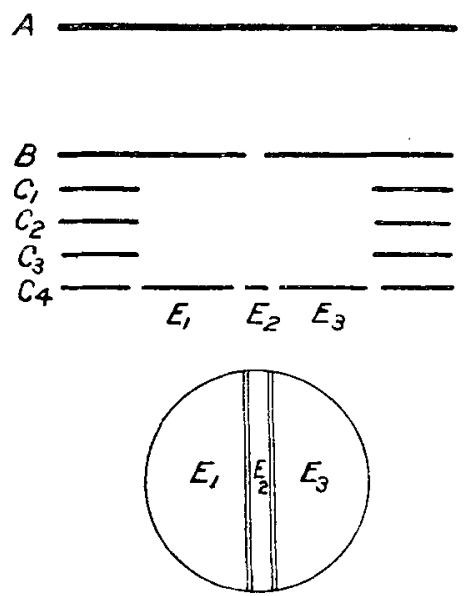

The electrodes $\mathrm{E}_{1}, \mathrm{E}_{2}, \mathrm{E}_{3}$ are mounted on ebonite fixed to the brass ring $\mathrm{C}_{4}$, and the upper surfaces turned so that they should all be in the same plane, parallel to the plates $A$ and $B$.

The electrodes $\mathrm{E}_{1}, \mathrm{E}_{2}, \mathrm{E}_{3}$ are sections of a disk $7 \cdot 6$ centimetres in diameter. The central electrode $E_{2}$ is a strip 4.5 millimetres wide insulated by gaps half a miliimetre wide from the electrodes $\mathrm{E}_{2}$ and $\mathrm{E}_{3}$.

It is essential that the field below $B$ should be perfectly uniform, and for this purpose the brass rings $\mathrm{C}_{1}, \mathrm{C}_{2}, \mathrm{C}_{3}$ are fixed at equal intervals apart between the plate $B$ and the ring $\mathrm{C}_{4}$, and maintained at constant potentials by attery of small accumulators. The positive terminal of the battery is connected to the ring $\mathrm{C}_{4}$ which is at zero potential, and the rings $\mathrm{C}_{1}, \mathrm{C}_{2}, \mathrm{C}_{3}$ and the plates $\mathrm{A}$ and $\mathrm{B}$ are connected to points of the battery which maintain them at negative potentials proportional to their distances from the lower ring $\mathrm{C}_{4}$. Thus the electrons arriving at the slit in the plate $B$ have aequired the final velocity corresponding to a constant electric force $\mathrm{Z}$, and continue to move under the same force from the slit to the electrodes $\mathrm{E}_{1}, \mathrm{E}_{2}, \mathrm{E}_{3}$. The stream diverges and a large proportion of the electrons are received on the electrodes $\mathrm{E}_{1}$ and $\mathrm{E}_{3}$, although the central electrode $\mathrm{E}_{2}$ is much wider than the slit in $B$. 
The charges $n_{1}, n_{2}, n_{3}$ acquired by the three electrodes were measured accurately by means of an induction balance. The apparatus for measuring the charges was arranged so that the potentials of the electrodes $\mathrm{E}_{1}, \mathrm{E}_{2}, \mathrm{E}_{3}$ deviated from zero only by very small fractions of a volt while the charges were being measured.

The principal electrical quantities to be determined experimentally are a series of values of the ratio $\mathrm{R}=n_{2} /\left(n_{1}+n_{2}+n_{3}\right)$, i.e. of the cbarge acquired by the central electrode to the total charge, corresponding to different electric forces $Z$ and different pressures $p$ of the gas, and of the transverse magnetic force which deflects the stream through a distance of 2.5 millimetres.

4. The value of the ratio $R$ may also be found theoretically when the energy of agitation of the charged particles in the stream is known, as in the case of ions where the energy of agitation is the same as that of the molecules of the gas. The calculations show that $R$ is, in this case, a function of the product $\mathrm{NeZ} / \Pi$, where $\mathrm{N}$ is the number of molecules per cubic centimetre of a gas at $760 \mathrm{~mm}$. pressure and temperature equal to that of the gas through which the stream is moving, $e$ the charge of the ion, $\mathrm{Z}$ the electric force, and $\Pi$ atmospheric pressure. This function $\mathrm{R}=f \mathrm{~N} e \mathrm{Z} / \Pi$ is the same for all gases, and is independent of the pressure of the gas and of the mass associated with the charge $e$.

$A$ comparison of the values of $R$ found experimentally with the values given by the theoretical investigation gives a method of determining the product $\mathrm{N} e$, A large number of experiments have already been made to detenmine this quantity, and the results have shown that the charge $e$ is the same as the charge of a monovalent ion in a liquid electrolyte.

Negative ions are formed when there is a small proportion of water vapour present in the gas, and with the smaller electric forces of the order 4 to 6 volts per centimetre the value of $R$ as found experimentally was in accordance with the results indicated by the theory.

Thus the conditions under which the charged particles in the stream have an energy of agitation equal to that of the molecules of the surrounding gas are easily attained and recognized by the fact that $R$ is independent of the pressure of the gas. The ratio $\mathbf{R}$ for a stream of negative ions may be found either experimentally or calculated by the theory of diffusion, and these values of $R$ in terms of $Z$ may be represented by means of a curve. This curve (shown in 
the diagram fig. 2) is the same for all gases and independent of the pressure, and will be referred to as the normal distribution curve.

Fig. 2.

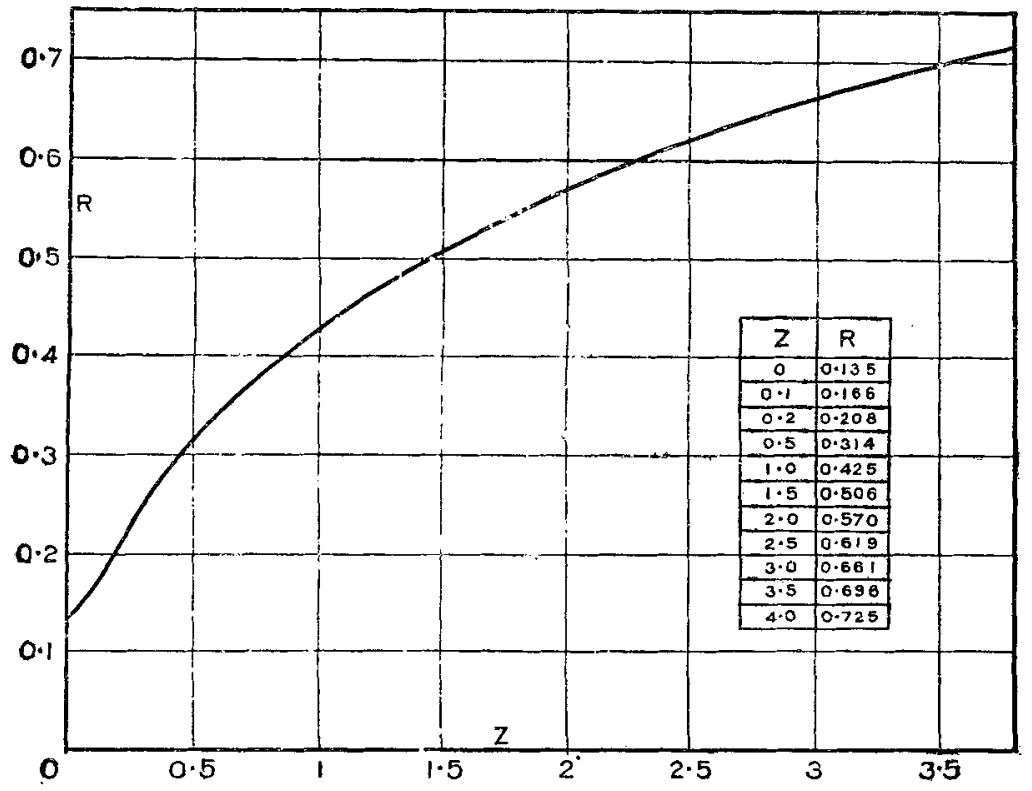

It is to be noticed that when the normal distribution of the stream is determined experimentally, it is necessary that the conditions should be arranged so that the self-repulsion of the ions does not contribute to the divergence of the stream. The currents should therefore be small and the experiments made at low pressures, since the effect of selfrepulsion is directly proportional to the intensity of the current and inversely proportional to the velocity of the ions.

5. Generally when the gases are very dry the electrons move freely between the molecules of the gas and they acquire an energy of agitation exceeding the value corresponding to thermal equilibrium with the gas, as shown by an abnormal divergence of the stream. If $k$ be the factor by which the energy of agitation of the electrons exceeds that of the molecules of the gas, the ratio $R$ becomes $\mathrm{R}=f(\mathrm{~N} e \mathrm{Z} / \mathrm{kI})$. Thus when the ratio $\mathrm{R}$ corresponding to a force $Z$ is found experimentally, the value of $k$ is equal to 


\section{Prof. J. S. Townsend and Mr. V. A. Bailey on}

the ratio $Z / Z_{1}$, where $Z_{1}$ is the force corresponding to $R$ as given by the normal distribution curve.

With a stream of electrons the ratio $R$ for a fixed force $Z$ diminishes as the pressure of the gas is reduced, and in this respect differs from a stream of ions.

6 . The velocity $W$ of the electrons in the direction of the electric force is determined by deflecting the stream with a transverse magnetic force. The magnetic force was produced by a current in two large circular coils, outside the air-tight case containing the apparatus shown in fig. 1 . The coils are fixed in positions to give a uniform magnetic freld in the space between the plate $B$ and the electrodes $E$. The two electrodes $\mathrm{E}_{2}$ and $\mathrm{E}_{3}$ were connected together and the current in the coils adjusted so that the charge acquired by $\mathrm{E}_{2}$ and $\mathrm{E}_{3}$ is equal to that acquired by $\mathrm{E}_{1}$. The centre of the stream is thus deflected to the centre of the narrow gap between $\mathrm{E}_{1}$ and $\mathrm{E}_{2}$, a distance of $2 \cdot 5$ millimetres.

If $\mathrm{H}$ be the magnetic force required to produce this deflexion, $a$ the distance from $\mathbf{B}$ to the electrodes $\mathbf{E}, b$ the distance between the centres of the two air gaps on either side of $E_{2}$, the velocity $W$ of the electrons in the direction of the electric force $\mathrm{Z}$ is given by the equation*

$$
\frac{\mathrm{HW}}{\mathrm{Z}}=\frac{b}{2 a}=\frac{1}{16} \text {. }
$$

There was a small difference between the values of the magnetic force required to deflect the centre of the stream to the centres of the two gaps, which showed that when there was no magnetic force the centre of the stream fell on a line one tenth of a millimetre from the centre of the electrode $\mathrm{E}_{2}$. This was no donbt due to a slight inaccuracy in the construction of the apparatus.

The value of $H$ used in obtaining $W$ from the above formula was the mean of the two forces required to deflect the stream to the centres of the two gaps.

7. It is necessary to show from the results of the experiments, how to distinguish between a stream consisting entirely of free electrons and a stream consisting partly of free electrons and partly of ions formed by electrons becoming: permanently associated with molecules of the gas.

In a stream of free electrons moving in a gas the final velocity $W$ in the direction of the elfetric force, and the final value of the factor $k$ by which the energy of agitation exceeds the normal, must depend only on the ratio of the

* Proc. Roy. Soc. A, lxxxvi. p. 571 (1912). 
electric force to the pressure. With the ranges of forces and pressures used in these experiments the above condition is satisfied by the values of $W$ and $k$ obtained with nitrogen and hydrogen, as hid previonsly been obtained with air. The results of the principal determinations are given in Tables I. and II., which are arranged in groups, each group corresponding approximately to one value of the ratio $\mathrm{Z} / p$. It will be seen that both $W$ and $k$ remain practically constant when the pressure and the force are reduced in the same proportion.

For certain forces and pressures the apparatus was not adapted for finding the velocities, so that there are some blank spaces in the column under W. For example, with a pressure of 20 millimetres and a force of $33 \cdot 4$ volts per centimetre in nitrogen, the magnetic force required to produce the deflexion of the stream necessary for measuring the velocity could only have been obtained by a current of more than 20 amperes which would have injured the coils. Also with the smaller electric forces the lateral divergence of the stream was, in some cases, so large that some of the stream was deflected on to the earth ring $\mathrm{C}_{4}$ by the magnetic field, which would have introduced an error in the determination of the velocity $W$.

With the large values of $Z / p$ electrons are generated in the stream by collisions of electrons with molecules. This effect does not introduce any error in the measurements of $k$ or W since this process of ionization increases by the same proportion the number of electrons in all parts of the stream.

8. Velocities $W$ in direction of electric forces $Z$, and factors $k$ by which energy of agitation of electrons exceed the normal value corresponding to $15^{\circ} \mathrm{C}$, , in nitrogen, hydrogen, and oxygen are given in the following tables.

9. In oxygen different values were obtained for $W$ and $k$ in the cases where the ratio $Z / p$ was the same, especially when $p$ was taken over ranges including large pressures, but with the smaller pressures and larger values of Z/p the discrepancies were not great.

Examples of determinations of the velocities $W$ and the quantities $k$ with electrons moving in oxygen are given in Table III., which show that both $W$ and $k$ tend to increase when $Z$ and $p$ are reduced in the same proportion.

This effect wonld occur if the electrons tended to become permanently associated with molecules or other small particles as they moved through the gas. Thus if electrons moved under a force $Z$ and pressure $p$ and a certain number 
880 Prof. J. S. Townsend and Mr. V. A. Bailey on

$\mathrm{W}$ in centimetres per second.

$\mathrm{Z}$ in volts per centimetre.

$p$ in millimetres of mercury.

Table I.-Nitrogen.

\begin{tabular}{|c|c|c|c|c|}
\hline$p$ & $z$. & $\mathrm{Z} / p$ & $k$. & $\mathrm{W} \times 10^{-5}$ \\
\hline $\begin{array}{l}20 \\
10\end{array}$ & $\begin{array}{l}8 \cdot 5 \\
4 \cdot 25\end{array}$ & $\begin{array}{l}0425 \\
0.425\end{array}$ & $\begin{array}{l}11.5 \\
10 \cdot 4\end{array}$ & $\begin{array}{l}5.85 \\
5.9\end{array}$ \\
\hline $\begin{array}{r}20 \\
10 \\
5\end{array}$ & $\begin{array}{c}16 \cdot 9 \\
8 \cdot 5 \\
4 \cdot 25\end{array}$ & $\begin{array}{l}0.845 \\
0.85 \\
0.85\end{array}$ & $\begin{array}{l}18 \cdot 9 \\
19 \cdot 1 \\
185\end{array}$ & $\begin{array}{l}7.77 \\
7.56 \\
-\end{array}$ \\
\hline $\begin{array}{c}20 \\
10 \\
5 \\
2 \cdot 5\end{array}$ & $\begin{array}{l}33+\frac{1}{16} \\
16.95 \\
4.25\end{array}$ & $\begin{array}{l}1.67 \\
1.69 \\
1.67 \\
170\end{array}$ & $\begin{array}{l}28 \cdot 2 \\
27.8 \\
290 \\
28 \cdot 3\end{array}$ & $\begin{array}{c}\overline{11 \cdot 1} \\
11 \cdot 1 \\
-\end{array}$ \\
\hline $\begin{array}{c}10 \\
5 \\
2 \cdot 5\end{array}$ & $\begin{array}{r}33 \cdot 7 \\
16 \cdot 9 \\
8 \cdot 4\end{array}$ & $\begin{array}{l}337 \\
338 \\
336\end{array}$ & $\begin{array}{l}36 \cdot 1 \\
37 \cdot 0 \\
35 \cdot 8\end{array}$ & $\begin{array}{l}19 \cdot 6 \\
19 \cdot 7 \\
19 \cdot 1\end{array}$ \\
\hline $\begin{array}{l}5 \\
2 \cdot 48 \\
1 \cdot 25\end{array}$ & $\begin{array}{r}337 \\
168 \\
8.4\end{array}$ & $\begin{array}{l}6771 \\
679 \\
673\end{array}$ & $\begin{array}{l}44 \cdot 9 \\
44 \cdot 9 \\
44 \cdot 1\end{array}$ & $\begin{array}{l}35 \cdot 6 \\
35 \cdot 1 \\
32 \cdot 2\end{array}$ \\
\hline $\begin{array}{l}2 \cdot 48 \\
1.25 \\
0.62\end{array}$ & $\begin{array}{r}33 \cdot 8 \\
16 \cdot 8 \\
8.5\end{array}$ & $\begin{array}{l}13 \cdot 6 \\
13 \cdot 4 \\
13 \cdot 7\end{array}$ & $\begin{array}{l}51: 3 \\
52 \cdot 0 \\
53 \cdot 0\end{array}$ & $\begin{array}{c}62 \cdot 4 \\
62 \cdot 5 \\
-\end{array}$ \\
\hline $\begin{array}{l}1 \cdot 26 \\
0 \cdot 622\end{array}$ & $\begin{array}{l}33 \cdot 9 \\
169\end{array}$ & $\begin{array}{l}26 \cdot 9 \\
27 \cdot 1\end{array}$ & $\begin{array}{l}66 \cdot 8 \\
68 \cdot 8\end{array}$ & $\begin{array}{l}110 \\
105\end{array}$ \\
\hline $\begin{array}{l}0 \cdot 625 \\
0.303\end{array}$ & $\begin{array}{l}33.9 \\
16.8\end{array}$ & $\begin{array}{l}5+3 \\
55 \cdot 6\end{array}$ & $\begin{array}{l}117 \\
1.21\end{array}$ & 181 \\
\hline
\end{tabular}

of them formed ions in passing from the plate $A$ to the plate $B$ in the apparatus shown in fig. 1, double this number would be formed if the electrons mored for the same distance through the gas at pressure $2 p$ under a force $2 \mathrm{Z}$. Thus, in an apparatus of fixed dimensions the greater the pressure of the gas the greater the number of ions that would be formed.

The state in which the proportion of ions to electrons in a oas is increasing with $p$ is thus easily recognized by the fact that $W$ and $k$ cannot be represented in terms of the ratio $\mathrm{Z} / \mathrm{p}$ alone.

If the ions which are formed are not stable, as is the case when the electron may be dissociated by collisions from the molecule or group of molecules which the ion comprises, 
the Motion of Electrons in Gases.

TABLe II.-Hydrogen.

\begin{tabular}{|c|c|c|c|c|}
\hline$p$ & $\mathrm{Z}$. & $\mathrm{Z} / p$ & $k$. & $W \times 10^{-3}$ \\
\hline $\begin{array}{l}40 \\
19 \cdot 8\end{array}$ & $\begin{array}{l}85 \\
4.35\end{array}$ & $\begin{array}{l}0.212 \\
0.221\end{array}$ & $\begin{array}{l}3 \cdot 72 \\
2 \cdot 87\end{array}$ & $\begin{array}{l}5.98 \\
6.28\end{array}$ \\
\hline $\begin{array}{l}40 \\
20 \\
10\end{array}$ & $\begin{array}{c}17 \cdot 0 \\
8 \cdot 5 \\
4 \cdot 25\end{array}$ & $\begin{array}{l}0.425 \\
0.425 \\
0.425\end{array}$ & $\begin{array}{l}4 \cdot 56 \\
4 \cdot 70 \\
4 \cdot 48\end{array}$ & $\begin{array}{l}8 \cdot 41 \\
8 \cdot 58 \\
8 \cdot 49\end{array}$ \\
\hline $\begin{array}{l}19 \cdot 75 \\
10 \\
5\end{array}$ & $\begin{array}{c}17 \cdot 5 \\
8 \cdot 5 \\
4 \cdot 25\end{array}$ & $\begin{array}{l}0.886 \\
0.850 \\
0.850\end{array}$ & $\begin{array}{l}8 \cdot 33 \\
7.83 \\
7.95\end{array}$ & $\begin{array}{l}11.25 \\
11.2 \\
11.1\end{array}$ \\
\hline $\begin{array}{l}19 \cdot 75 \\
10 \\
5 \\
2.53\end{array}$ & $\begin{array}{c}35.0 \\
17.0 \\
8.5 \\
4.25\end{array}$ & $\begin{array}{l}1.77 \\
1.70 \\
1.70 \\
1.68\end{array}$ & $\begin{array}{l}13.75 \\
12.8 \\
13.0 \\
13.3\end{array}$ & $\begin{array}{l}15 \cdot 5 \\
15.2 \\
15 \cdot 3 \\
14 \cdot 8\end{array}$ \\
\hline $\begin{array}{l}10 \\
5 \\
2 \cdot 53 \\
1.24\end{array}$ & $\begin{array}{c}34.0 \\
17.0 \\
8.5 \\
4.25\end{array}$ & $\begin{array}{l}3 \cdot 40 \\
3 \cdot 10 \\
3 \cdot 36 \\
3 \cdot 42\end{array}$ & $\begin{array}{l}20 \cdot 4 \\
20 \cdot 2 \\
20 \cdot 2 \\
20 \cdot 1\end{array}$ & $\begin{array}{c}21.5 \\
21.8 \\
21.5 \\
--\end{array}$ \\
\hline $\begin{array}{l}5 \\
2 \cdot 53 \\
1 \cdot 24 \\
0 \cdot 627\end{array}$ & $\begin{array}{c}340 \\
17.0 \\
8.5 \\
4.25\end{array}$ & $\begin{array}{l}6 \cdot 80 \\
6 \cdot 72 \\
6.85 \\
6.80\end{array}$ & $\begin{array}{l}32 \cdot 2 \\
31 \cdot 2 \\
31 \cdot 7 \\
31 \cdot 5\end{array}$ & $\begin{array}{c}32 \cdot 5 \\
32 \cdot 1 \\
30 \cdot 0 \\
-\end{array}$ \\
\hline $\begin{array}{l}2.52 \\
1 \cdot 24 \\
0.625\end{array}$ & $\begin{array}{r}34.0 \\
17 \cdot 2 \\
8.5\end{array}$ & $\begin{array}{l}13.5 \\
13 \cdot 9 \\
13 \cdot 6\end{array}$ & $\begin{array}{l}50 \cdot 7 \\
56 \cdot 7 \\
58 \cdot 6\end{array}$ & $\begin{array}{c}49 \cdot 4 \\
48 \cdot 8 \\
-\end{array}$ \\
\hline $\begin{array}{l}1 \cdot 24 \\
0.63\end{array}$ & $\begin{array}{l}3+0 \\
17 \cdot 2\end{array}$ & $\begin{array}{l}27 \cdot 4 \\
27 \cdot 3\end{array}$ & $\begin{array}{l}97 \cdot 1 \\
98 \cdot 0\end{array}$ & $\begin{array}{r}103 \\
-\end{array}$ \\
\hline
\end{tabular}

TABLe III.-Oxygen.

\begin{tabular}{|c|c|c|c|c|}
\hline$p$ & Z. & $\mathrm{Z} / \mathfrak{p}$ & $k$. & $\mathrm{W} \times 10^{-\overline{5}}$ \\
\hline $\begin{array}{l}10 \\
4.9 \\
2.5\end{array}$ & $\begin{array}{c}17 \\
8.5 \\
4 \cdot 25\end{array}$ & $\begin{array}{l}1 \cdot 7 \\
1 \cdot 73 \\
1 \cdot 7\end{array}$ & $\begin{array}{c}9 \cdot 44 \\
13 \cdot 5 \\
15.2\end{array}$ & $\begin{array}{l}18 \\
27 \\
28 \cdot 5\end{array}$ \\
\hline $\begin{array}{l}10 \\
4.9 \\
2.5\end{array}$ & $\begin{array}{l}84 \\
17 \\
8 \cdot 5\end{array}$ & $\begin{array}{l}3 \cdot 4 \\
3 \cdot 47 \\
3 \cdot 4\end{array}$ & $\begin{array}{l}29 \cdot 8 \\
36 \cdot 2 \\
37 \cdot 2\end{array}$ & $\begin{array}{l}28 \\
33 \cdot 5 \\
34: 5\end{array}$ \\
\hline $\begin{array}{l}4 \cdot 9 \\
2 \cdot 5 \\
1 \cdot 26\end{array}$ & $\begin{array}{l}34 \\
17 \\
855\end{array}$ & $\begin{array}{l}6.94 \\
6.8 \\
6.75\end{array}$ & $\begin{array}{l}40 \cdot 1 \\
45 \cdot 2 \\
47 \cdot 2\end{array}$ & $\begin{array}{l}35 \\
38.5 \\
-\end{array}$ \\
\hline
\end{tabular}




\section{Prof. J. S. Townsend and Mr. V. A. Bailey on}

a final state of equilibrium is obtained in which the proportion of ions to electrons is constant. In this case $W$ and $k$ would be functions of $\mathrm{Z} / p$ alone. A stream of this kind may be distinguished from a stream comprising only free electrons, by the effects obtained with magnetic forces*.

In all cases the proportion of ions to electrons in a gas at constant pressure diminishes as the electric force increases. This holds even in the case where water vapour is present. With the forces and pressures used in these experiments there does not appear to be any indication of the presence of ions in nitrogen or hydrogen.

The following experiments indicated in a direct manner the presence of ions with electrons in a stream in oxygen. The ratio of the charges received by the electrodes $\mathrm{E}_{2}$ and $\mathrm{E}_{3}$ to that received by $\mathbf{E}_{1}$ in the apparatus fig. 1, was determined while large magnetic forces were acting which tended to deflect the stream towards the electrode $\mathrm{E}_{1}$. The grentest force which it was possible to use would lave been too small to produce an appreciable deflexion of particles having masses of the same order as the mass of a molecule.

When the magnetic force was incrensed to the maximum available, the charges $n_{2}+n_{3}$ were about one per cent. of the charge $n_{1}$ in the experiments with nitrogen and air, but with oxygen a much higher proportion remained on the electrodes $\mathrm{E}_{2}$ and $\mathrm{E}_{3}$ under sinilar conditions.

It had previously been observed that electrons tended to form inns in moving through imperfectly dried gases, the effect being particularly marked with the smaller values of $\mathrm{Z} / p$. This, however, does not seem to be the cause of the presence of ions in the oxygen used in these experiments.

The oxygen was obtained by the electrolysis of barium lydrate, and was dried in a flask with phosphorus pentoxide. Practically the same results were obtained with two specimens of the gas, one of which had been in the drying flask for seven days and the other for fourteen days. It is therefore improbable that the effect was due to water vapour. Further experiments are being made on this point and will be reserved for a future communication.

The velocity $W$ and the quantity $k$ obtained in these experiments with oxygen at the lower pressures and the higher forces are probably not much different from the exact ralues for streams of electrons, and these will be used for the present in order to compare oxygen with nitrogen and hydrogen.

* J. S. Townsend and H. T. Tizard, Proc. Roy. Soc. A, lxxxvii. (1912). 
10. The experimental results for the three gases may be shown by means of curves representing $W$ and $k$ in terms of $\mathrm{Z} / p$. The values of $\mathrm{W}$ in the three gases corresponding to the smaller values of $Z / p$ are given by curves fig. 3 , and

Fig. 3.

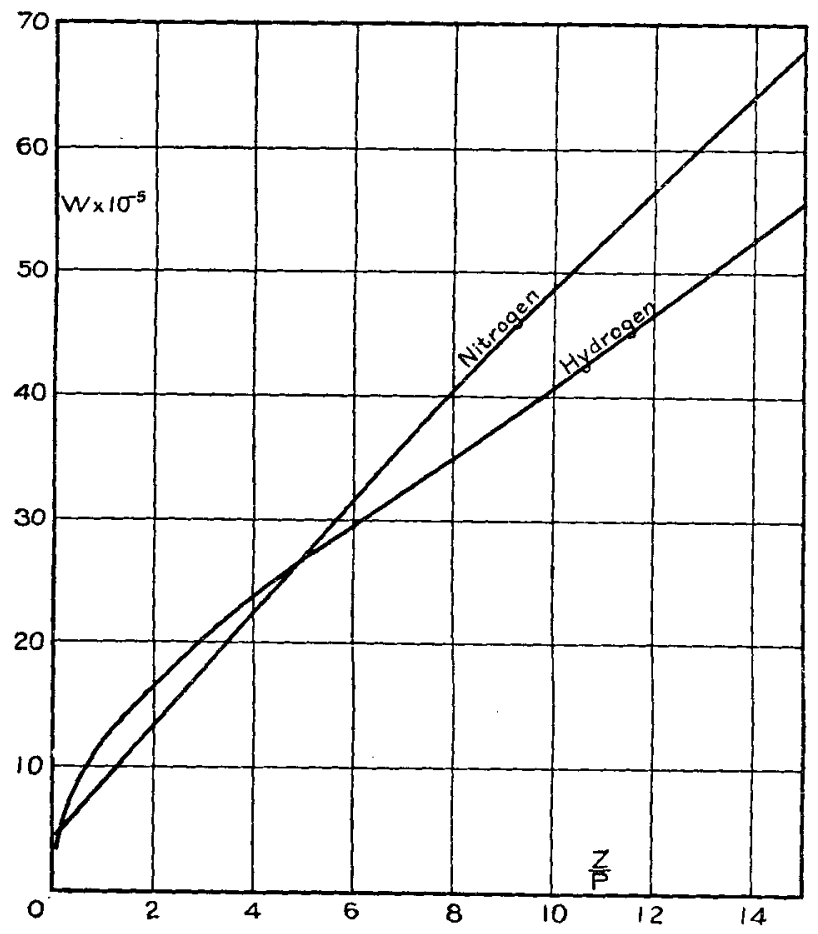

for the larger values of $Z / p$ by the curves fig. 4 . The values of $k$ are similarly represented by the curves figs. 5 and 6 . Since the results obtained with oxygen are not as accurate as those obtained with nitrogen and hydrogen, the values of $W$ and $k$ for that gas are represented by dotted curves.

11. The results of the experiments may be used to find the mean free path $l$ of an electron between collisions with molecules, and the distance $\sigma$ between the centre of the molecule and the centre of the electron when a collision occurs is found from the relation $l=\frac{1}{\pi v \sigma^{2}}, \nu$ being the number of molecules per cubic centimetre of the gas. 
884 Prof. J. S. Townsend and Mr. V. A. Bailey on

It is difficult to set a limit to the distance between the centres at which the force between the molecule and the electrons would be sufficient to deflect the electron through a small definite angle, but the following definitions may be adopted for the mean free path $l$ and the distance $\sigma$ which may be called the radius of the molecule as found by these calculations. As the velocity of agitation of the electrons is

Fig. 4.

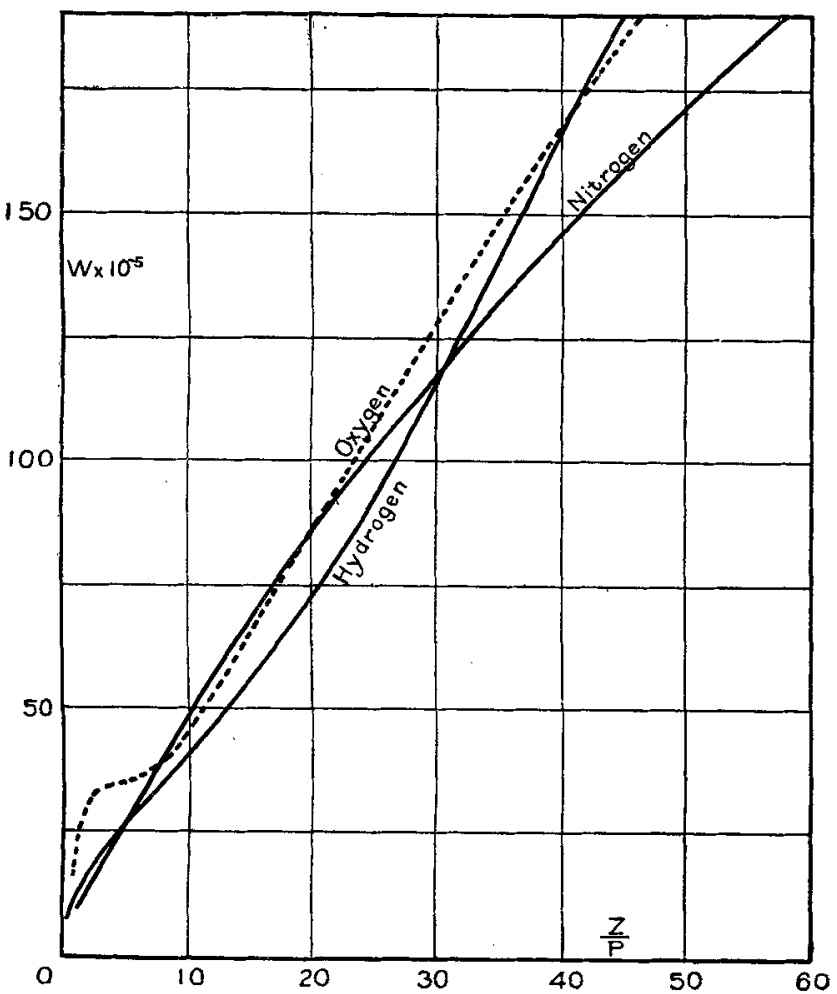

very large compared with the velocity of agitation of the molecules, the latter may be considered to be at-rest.

If a number of electrons be uniformly distributed in a stream of sectional area $\pi s^{2}$ and move with the same velocity in the same direction towards a molecule, the centre of the stream being in line with the centre of the molecule, the average velocity of the electrons after colliding will have a component in the opposite direction to the original motion if $s$ is very small, as a large proportion of the electrons will 
have their volocities reversed. If $s$ is very large the greater proportion will pass by the molecule and their direction of motion will be only slightly affected, and in this case the average velocity after collision will have a component in the original direction of motion. There is one value of $s$ for which the average component of the velocities of the electrons after collision will be zero, and this is the value taken in this investigation as $\sigma$, which may be called the radius of the molecule for brevity.

Fig. 5 .

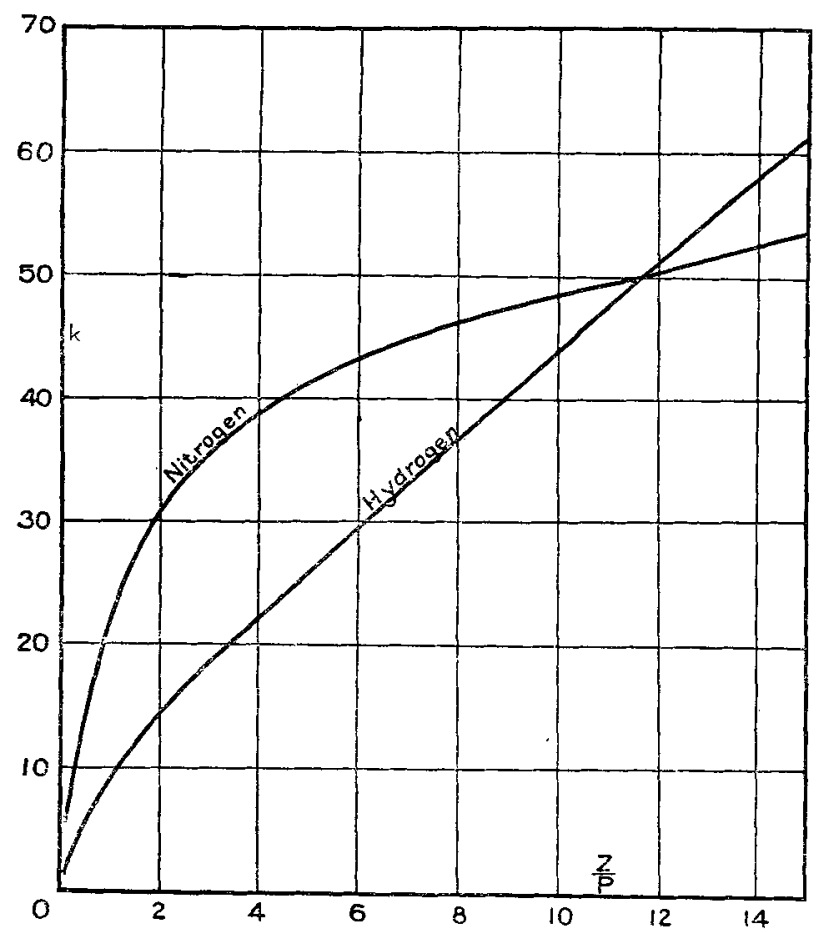

Similarly if a large number of electrons move in the same direction initially in a gas, the mean value of the components of the velocities in any direction is zero after all the electrons have collided with molecules, and the mean distance they travel in the original direction of motion is the mean free path $l$.

12. With the above specification of the mean free path of an electron moving in a gas under an electric force $\mathrm{Z}$, 
886 Prof- J. S. Townsend and Mr. V. A. Bailey on the velocity is $W=\frac{Z e}{m} \times \frac{l}{u} \times 0.815$, which formula may be derived from a more general formula* for the velocity of ions in gases given by Langevin.

All the quautities in this formula are known except $l$, $e / m$ being $1.77 \times 10^{7}$ the value of this ratio for electrons, and $u=1 \cdot 15 \times 10^{7} \sqrt{k}$, since the mean velocity of agitation of a

Fig. 6.

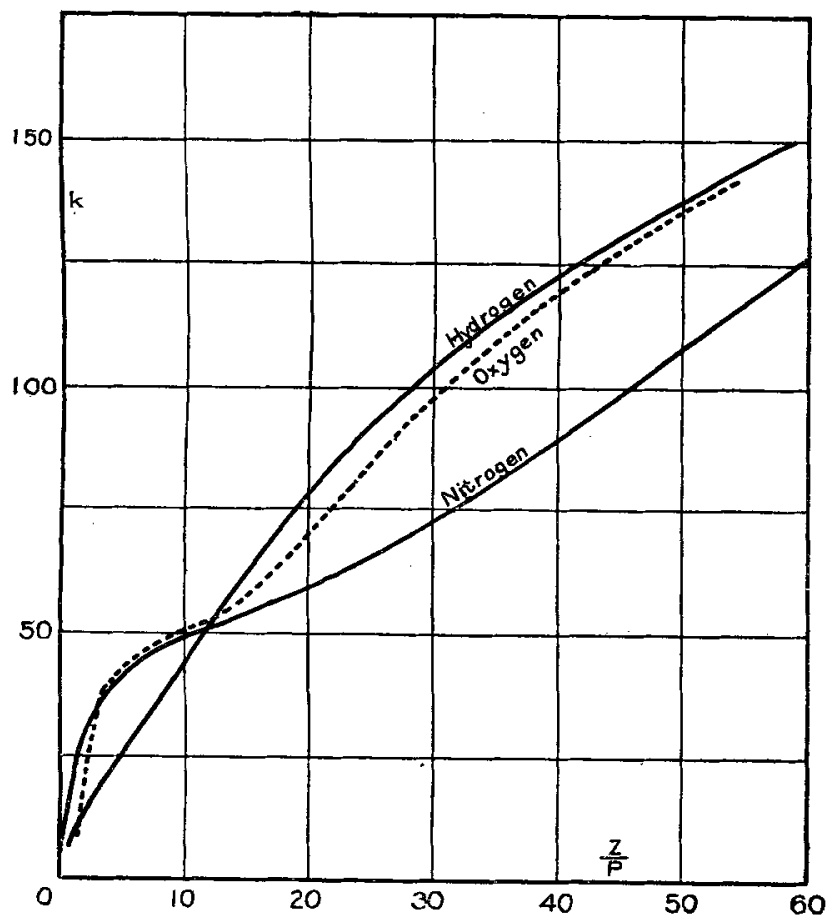

particle having the same mass as an electron is $1.15 \times 10^{7}$ centimetres per second when in thermal equilibrium with molecules of a gas at $15^{\circ} \mathrm{C}$.

Taking one millimetre of mercury as the pressure of the gas, the values of $l$ for the different gases as obtained from the above formula are given in Tables IV., V., and VI. The values of $l$ for air have also been calculated and are given in Table VII.

The values of $\sigma$ given in the tables are obtained from the formula $l=1 / \pi \nu \sigma^{2}, \nu$ the number of molecules per cubic * Townsend, 'Electricity in Gases,' p. 180. 
centimetre of a gas at one millimetre pressure and $15^{\circ} \mathrm{C}$. being taken as $3.46 \times 10^{16}$.

The quantities $\sigma_{1}$ which are also given are the radii of the molecules deduced from the formula given by Jeans* for the viscosity of a gas, taking the number of molecules per cubic centimetre at normal pressure and temperature as $2 \cdot 77 \times 10^{19}$ corresponding to the above value of $\nu$.

In the following fables $\mathrm{Z}$ is in volts per cm., $p$ in mm. of mercury, $W$ and $u$ in ems. per sec., and $l$ and $\sigma$ in cms.

\section{TABLE IV.-Nitrogen.}

$$
\sigma_{1}=1.88 \times 10^{-8} \text {. }
$$

\begin{tabular}{|c|c|c|c|c|c|c|}
\hline$\frac{\boldsymbol{Z}}{p}$. & $k$. & $W \times 10^{-3}$ & $u \times-10^{6}$ & $t \times 100$ & $\sigma \times 10^{8}$. & $f$. \\
\hline 100 & 180 & - & 154 & - & - & - \\
\hline 60 & 126 & 193 & 129 & $2 \cdot 89$ & $1 \cdot 78$ & 0.9775 \\
\hline 50 & 108 & 171 & $119 \cdot 4$ & $2 \cdot 83$ & 1.80 & 0.9794 \\
\hline 40 & 89 & 146 & $108 \cdot 3$ & $2 \cdot 75$ & 1.82 & 0.9818 \\
\hline 30 & 72.5 & 117 & 98 & 267 & $1 \cdot 85$ & 0.9862 \\
\hline 20 . & $59 \cdot 5$ & 86 & $88 \cdot 5$ & $2 \cdot 66$ & $1 \cdot 86$ & 0.9905 \\
\hline 10 & $48 \cdot 5$ & 48.5 & 80 & 269 & $1 \cdot 84$ & 0.99636 \\
\hline 5 & $41 \cdot 3$ & 27 & 739 & 577 & $1 \cdot 82$ & 0.99869 \\
\hline 3 & 35.5 & 17.8 & $68 . \tilde{5}$ & $2 \cdot 82$ & $1 \cdot 80$ & 0.99934 \\
\hline 2 & 30.5 & $13 \cdot 1$ & 635 & 288 & 1.78 & 0.99960 \\
\hline 1 & 21.5 & $8 \cdot 7$ & 535 & $3 \cdot 20$ & $1 \cdot 69$ & 0.09976 \\
\hline 0.5 & 13 & 6.2 & $41 \cdot 4$ & 355 & $1 \cdot 61$ & 0.99980 \\
\hline 0.25 & $7 \cdot 5$ & $5 \cdot 15$ & $31 \cdot 5$ & $4 \div 0$ & $1 \cdot 43$ & 0.99976 \\
\hline
\end{tabular}

TABLE V.-Hydrogen.

$\sigma_{1}=1 \cdot 34 \times 10^{-8}$.

\begin{tabular}{|c|c|c|c|c|c|c|}
\hline$\frac{\mathrm{Z}}{p}$. & $k$. & $W \times 10^{-5}$ & $u \times 10^{-6}$. & $l \times 100$ & $\sigma \times 10^{8}$ & $f$ \\
\hline 56 & 146 & 248 & 139 & $4 \cdot 27$ & $1 \cdot 47$ & 0.9686 \\
\hline 50 & 138 & 217 & $134 \cdot 8$ & 407 & 1.50 & 0.9744 \\
\hline 40 & 123 & 160 & $127 \cdot 5$ & $3 \cdot 67$ & 159. & 0.9834 \\
\hline 30 & 104 & 106 & 117 & $2 \cdot 87$ & $1 \cdot 70$ & 0.9921 \\
\hline 20 & 78 & 72 & $101 \cdot 5$ & 2.53 & 1.90 & 0.99524 \\
\hline 10 & 44 & 40.7 & $76 \cdot 2$ & $2 \cdot 15$ & 207 & 0.99742 \\
\hline 5 & $25 \cdot 5$ & 267 & 58 & $2 \cdot 14$ & 2.07 & 0.99814 \\
\hline 3 & $18 \cdot 6$ & $20 \cdot 2$ & $49 \cdot 5$ & $2 \cdot 31$ & 200 & 099858 \\
\hline 1.5 & 12 & $14 \cdot 4$ & $39 \cdot 8$ & 266 & 1.86 & 0.99894 \\
\hline 1 & 9 & 119 & $34 \cdot 5$ & $2 \cdot 86$ & 1.79 & 0.99905 \\
\hline 0.5 & $5 \cdot 2$ & $9 \cdot 0$ & $26 \cdot 2$ & 325 & $1 \cdot 67$ & 0.99904 \\
\hline 0.25 & $3 \cdot 1$ & $6 \circ 0$ & $20 \cdot 2$ & $3 \cdot 64$ & 1.59 & 0.99914 \\
\hline
\end{tabular}

* Jeans, 'Dynamical Theory of Gases,' p. 276 (1921). 
888 Prof. J. S. Townsend and Mr. V. A. Bailey on

$$
\begin{gathered}
\text { Table VI.-Oxygen. } \\
\sigma_{1}=1.81 \times 10^{-8} .
\end{gathered}
$$

\begin{tabular}{|c|c|c|c|c|c|c|}
\hline$\frac{Z}{p}$. & $k$. & $W \times 10^{-5}$ & $u \times 10^{-6}$ & $l \times 100$ & $\sigma \times 10^{*}$. & $f$. \\
\hline 50 & 136 & 201 & 134 & 374 & 1.57 & 0.9775 \\
\hline 20 & 70 & 86 & 96 & 289 & 1.78 & 0.9919 \\
\hline 14 & $55 \cdot \overline{5}$ & 61 & $85 \cdot 5$ & $2 . \overline{7} 7$ & 1.89 & $0 \cdot 9949$ \\
\hline 10 & 50 & 46 & $81 \cdot 2$ & $2 \cdot 58$ & $1 \cdot 88$ & 0.9968 \\
\hline 6 & 45 & 36 & $77 \cdot 1$ & 322 & $1 \cdot 69$ & 0.9978 \\
\hline 2 & $22 \cdot 5$ & 30 & $54 \cdot 5^{\circ}$ & 56 & $1 \cdot 27$ & 0.9969 \\
\hline
\end{tabular}

\begin{tabular}{|c|c|c|c|c|c|c|}
\hline$\frac{Z}{p}$. & Li: & $\mathrm{W} \times 10^{-5}$ & $u \times 10^{-6}$. & $l \times 100$ & $\sigma \times 10^{8}$ & $f$ \\
\hline 100 & 160 & 270 & 145 & 272 & 1.84 & 0.9654 \\
\hline 50 & 102 & 173 & 116 & $2 \cdot 78$ & $1 \cdot 82$ & 0.9778 \\
\hline 20 & 57 & 90 & 87 & 271 & $1 \cdot 84$ & 0.9893 \\
\hline 10 & 46 & 52 & 78 & 282 & 1.80 & 0.9956 \\
\hline 5 & 38 & 30 & 71 & 296 & $1 \cdot 76$ & 099823 \\
\hline 2 & 22 & 175 & 54 & 328 & 167 & 0.99897 \\
\hline$\overline{1}$ & 11 & $12 \cdot 5$ & 38 & 330 & 167 & 099894 \\
\hline 0.5 & $5 \cdot 7$ & 9 & 27 & $3 \cdot 37$ & $1 \cdot 65$ & 0.99891 \\
\hline
\end{tabular}

$$
\begin{gathered}
\text { TABLE VII.-Air. } \\
\sigma_{1}=1.85 \times 10^{-x}
\end{gathered}
$$

The values of $\sigma$ depend on the velocity $u$ with which the electron collides with a molecule, and attain a maximum value within the range of the velocities that bave been measured.

It will be noticed that for velocities $u$ less than $1.2 \times 10^{8}$ $\sigma$ is greater for hydrogen than for nitrogen, so that the field of force round a molecule as measured by a charged particle of small mass is wider for a molecule of hydrogen than for a molecule of nitrogen.

13. The determination of the velocities may be used to find what proportion of the total energy of an electron is lost by a collision with a molecule. An approximate estimate of the average loss of energy at each collision to the average energy $\left(m u^{2} / 2\right)$ of an electron is easily obtained. In passing through a distance of one centimetre in the direction of the electric force in the time $1 / \mathrm{W}$, the electron acquires the amount of energy $Z e$, and in the steady state when the motion has attained the final value corresponding to the force $\mathrm{Z}$ this energy is transferred to the molecules of the gas. The total path traversed by the electron in the time 
$1 / \mathrm{W}$ is $u / \mathrm{W}$, and the number of collisions with molecules is $u / l W$, so that the average loss of energy of the electron due to a collision is (KelW $) / u$. Hence the proportion of the total energy $\left(m u^{2}\right) / 2$ wbich is lost in a collision is

$$
\frac{2 \mathrm{Z} e l \mathrm{~W}}{u m u^{2}} \text {, which reduces to } \frac{2}{0 \cdot 815} \times \frac{\mathrm{W}^{2}}{u^{2}} \text {. }
$$

Thus when $u$ is ten times $W$, between two and three per cent. of the energy of the electron is lost in a collision. It will be noticed that the mean free path $l$ does not enter into the fiual calculation, so that the result is independent of the linear dimensions which may be attributed to a molecule.

The loss of energy of the electron, although comparatively small, is very much greater than the loss that would be sustained by a small sphere moving with the velocity $u$ in colliding with a large sphere, if both spheres were perfectly elastic. The energy lost by the electron appears as an increase of the internal energy of the molecule such as a vibration set up in some of the constituent electrons. Were it not for this effect the velocities of agitation $u$ would have attained very much higher values than those observed, and the velocities $W$ would have been less, since $W$ is inversely proportional to $u$.

The effect produced by a small degree of inelasticity in the collisions between spheres has been investigated by Pidduck *. If $f^{\prime}=\frac{1}{2}(1+\mu), \mu$ being the coefficient of restitution as in collisions between inelastic spheres, the formula for the value of $f$ in terms of $k$ and $W$ which is applied by Pidduck to the case of the motion of electrons may be written in the form

$$
f=1-\frac{W^{2}}{u^{2}}+\frac{k-1}{k} \cdot \frac{m}{\mathrm{M}},
$$

where $m$ is ths mass of an electron, and M the mass of a molecule of the gas.

The values of $f$ for the different velocities of impact $u$ are given in Tables IV., V., VI., and VII. It will be noticed that $f$ decreases as $u$ increases, which indicates that the greater the velocity of impact the larger the proportion of the energy of the electron which is converted into internal molecular energy.

14. It is of interest to consider the mode in which an electron may lose its energy in colliding with a molecule from the point of view of the quantum theory of radiation. According to this theory a molecule can absorb energy from

* F. B. Pidduck, Proc. Lond. Math. Soc. vol. xv. pp. 87-127 (1915-16). Phil. Mag. S. 6. Vol. 42. No. 252. Dee. 1921. $3 \mathrm{~N}$ 
an electromagnetic wave only in definite quantities which are proportional to the frequency $n$ of the radiation. Thus if the molecules of a gas have a free period of vibration of frequency $n$, they can only absorb energy in amounts which are exact multiples of the quantity $h n, h$ being Planck's constant.

It is convenient to express this quantity in volts, that is, the energy acquired by an electron moving under the action of an electric force between two points differing in potential by a certain number of volts. It $n$ be the frequency of the yellow sodiam line, the quantity of energy $h n$ corresponds to a fall of potential of about 2 volts.

When electrons moving with high velocities collide with molecules the frequency of the radiation which is excited depends on the velocity, and if the quantam theory be extended to cases where energy is supplied to molecules by the impacts of electrons, the highest frequency which could be excited by an electron moving with a velocity $u$ is obtained from the relation $h n=\left(m u^{2}\right) / 2$. Also in a gas containing molecules which have no free periods of vibration less than that of the light in the visible spectrum, they would absorb no energy from electrons moving with velocities smaller than that corresponding to potentials of about 2 volts.

The mean velocity of agitation of electrons corresponding to the various values of the ratio $\mathrm{Z} / p$ may easily be obtained in volts from the values which have been found for the quantity $k$. In a gas at $15^{\circ} \mathrm{C}$. the energy of agitation of the molecules corresponds to a fall of potential of $1 / 27$ th of a volt, so that $k / 27$ is the energy of the electrons expressed in volts. Thus in nitrogen at a millimetre pressure the value of $k$ is 54 for electrons moving under a force of $15 \cdot 2$ volts per centimetre, so that the mean velocity of agitation corresponds to a potential fall of 2 volts. In this case the total number of collisions made by an electron with molecules $(u) \mathrm{W} l)$ is about 470 in moving through a distance of one centimetre in the direction of the force and the average loss of energy in each collision is approximately 30 volt.

In order to explain the loss of energy of electrons due to collisions with molecules on this theory, it is necessary to suppose that in a small proportion of the total number of collisions there is a comparatively large loss of energy and in most of the collisions there is no loss (excepting the extremely small loss corresponding to the momentum transferred from the electron to the molecule, and the loss by radiation due to acceleration of the electron, both of which may be neglected in comparison with the observed effect). 
The large losses of energy could only occur when the electron collides with velocities exceeding those corresponding to $h n$, where $n$ is the frequency of radiation which is absorbed by the gas. In hydrogen and nitrogen there is no absorption of radiant energy in the visible or infrit-red spectrum. In the ultra-violet spectrun nitrogen is slightly opaque to rays of which the values of $h n$ are between 6.4 and 9.4 volts, but it is uncertain whether hydrogen absorbs rays in this part of the spectrum.

The velocities of the electrons are distributed about the mean velocity $u$ as in the case of molecules, but the law of distribution is not the same in the two cases. If the Maxwellian distribution be assumed in the case of the electrons an upper limit may be found to the number of collisions in which the velocity exceeds the mean velocity by a large factor. It thus appears that with a mean velocity of about 2 volts $(k=54)$ there may be a suficient number of collisions with a velocity of 6.4 volts to account for the average loss of energy of electrons in colliding with molecules of nitrogen. But the loss of energy is not explained on this theory when the electrons are moving with smaller mean velocities corresponding to values of $k$ of order 10 , since the number of possible collisions that occur with velocities exceeding 6.4 volts is so small in these cases.

When a large proportion of the energy of an electron is lost in each collision the quantity $k$ is comparatively small and $\mathrm{W}$ is comparatively large provided no ions are formed. In order that an ion may be formed the electrons must not rebound from the molecule after a collision, and the tendency to form ions is greatest when the molecules absorb a large proportion of the energy of the electrons. Also it is found experimentally that ions are only formed (even in the presence of water-vapour) when the electrons are moving with comparatively small velocities, so that in order to account for the formation of ions it is necessary to suppose that the molecules can absorb small quantities of energy. Hence the quantum theory indicates that large numbers of ions may be formed when the gas contains impurities which absorb radiant heat. The experiments are in agreement with the theory on this point as it has been found that ions are not formed in hydrogen and nitrogen, which are very diathermanous, but are rapilly formed in gases containing water-vapour or carbon dioxide which are very opaque to thermal radiation.

In conclusion we desire to express our thanks to Mr. B. Lambert for having supplied us with a quantity of carefully prepared nitrogen for use in these experiments. 